\title{
AUTORREGULAÇÃO NA APRENDIZAGEM DE UMA LÍNGUA ESTRANGEIRA: ESTUDOS BEM SUCEDIDOS NA LICENCIATURA EM LETRAS/FRANCÊS
}

RESUMO: No prolongamento de um estudo anterior sobre o uso de estratégias por alunos desistentes de licenciatura em francês, analisam-se, aqui, documentos reflexivos produzidos na disciplina "Aprender a Aprender Línguas Estrangeiras" por estudantes que obtiveram excelente êxito nas aulas de língua. Foram identificadas e analisadas, nessas produções, as ocorrências de estratégias ligadas às atividades de aprendizagem (plano do "estudar"), bem como aquelas ligadas às atividades linguageiras (plano do "comunicar"). A comparação com os resultados do estudo anterior mostrou que, além de usarem um número significativamente mais elevado de estratégias, os alunos bem sucedidos articulam melhor seus esforços de estudo com seu processo de comunicação, avaliando e regulando as estratégias voltadas para a aprendizagem em função das informações obtidas no uso de estratégias voltadas para a comunicação e vice-versa, com impacto claramente positivo para sua proficiência na língua. A pesquisa permitiu, assim, depreender ações que parecem favorecer a autorregulação dos aprendentes.

PALAVRAS-CHAVE: Estratégias de aprendizagem de línguas; Avaliação formativa; Autorregulação.

\section{INTRODUÇÃO}

O presente trabalho, desenvolvido no âmbito dos estudos do Grupo de pesquisa "Avaliação da/na Aprendizagem de Línguas" (AVAL) ${ }^{1}$, está vinculado a um projeto de pesquisa intitulado "Estudos bem-sucedidos na licenciatura em Letras/Francês: a autorregulação na aprendizagem da língua"². Esse projeto tinha

\footnotetext{
* Docente da Faculdade de Letras Estrangeiras Modernas e do Programa de Pós-graduação em Letras do Instituto de Letras e Comunicação, Universidade Federal do Pará. E-mail: mycunha@gmail.com

** Graduanda do curso de Letras com habilitação em Língua Francesa da Universidade Federal do Pará. Bolsista PIBIC. E-mail: kamira.oliveira@gmail.com

${ }^{1} \mathrm{O}$ grupo, cadastrado no CNPq e vinculado à linha de pesquisa "Ensino/Aprendizagem de Línguas" do Programa de Pós-Graduação em Letras-Linguística da Universidade Federal do Pará. As investigações empreendidas nos diversos subprojetos do grupo partilham o principal propósito de entender como práticas de avaliação e práticas de ensino-aprendizagem se inter-relacionam na área de línguas.

${ }^{2}$ O referido projeto foi realizado com o apoio do Programa PIBIC.
} 
por objetivo principal ampliar o conhecimento a respeito dos processos de autorregulação na aprendizagem de uma língua estrangeira, descrevendo fatores

que os favorecem. Mais especificamente, visava a: a) identificar, no discurso de aprendentes bem sucedidos na aprendizagem da Língua Francesa 1, em nossa faculdade, referências a processos de autorregulação; b) depreender nesses discursos fatores que favoreçam práticas de autorregulação na aprendizagem, distinguindo o plano da regulação da aprendizagem e o da regulação da atividade linguageira, na análise desses processos; c) cotejar os dados obtidos com aqueles que foram evidenciados em estudo anterior junto a um público de alunos desistentes, de modo a ressaltar semelhanças ou diferenças.

Partiu-se da hipótese de que esses aprendentes bem sucedidos, apesar das dificuldades encontradas no estudo da língua alvo, souberam identificar seus problemas em relação aos objetivos pretendidos e, valeram-se, para encontrar modos adequados de solucioná-los, de determinados procedimentos de regulação que alunos com dificuldade não utilizam, como mostrou um estudo anterior sobre as práticas de alunos desistentes (ver CUNHA, 2014). Naquele estudo havíamos procurado descrever fatores que inibissem os processos de autorregulação, inerentes às práticas de avaliação formativa. Embora os sujeitos pesquisados tivessem consciência da importância do uso de estratégias metacognitivas para melhorar seu domínio da língua estrangeira, aquele estudo permitiu evidenciar a ausência de efetivos processos de autorregulação em suas práticas e seu efeito na aprendizagem. De acordo com CUNHA (2014), os aprendentes que não conseguem analisar aquilo que fazem em termos comunicativos, isto é, que não têm clareza em relação aos objetivos comunicativos da aprendizagem pretendidos e os reduzem a objetivos linguísticos, também têm dificuldade em direcionar adequadamente suas estratégias de aprendizagem. Ficou claro, afinal, que a regulação das atividades de aprendizagem está interligada à das atividades linguageiras e que ambos os tipos de atividades regulatórias se dão mutuamente sentido.

O presente estudo estabeleceu uma comparação entre as práticas dos participantes do estudo anterior e alunos bem sucedidos no estudo da língua, contribuindo assim para a discussão dos processos regulatórios. Apresentaremos aqui as bases teóricas sobre as quais nos apoiamos, antes de descrever os procedimentos metodológicos adotados e de analisar os dados gerados.

\section{PRESSUPOSTOS TEÓRICOS}

A avaliação faz parte do processo de ensino/aprendizagem. Luckesi (2008, p. 66) opõe a avaliação à verificação, considerando que "a avaliação da aprendizagem existe propriamente para garantir a qualidade da aprendizagem do aluno. Ela tem a função de possibilitar uma qualificação da aprendizagem do educando". Para ele, a verificação detém-se apenas na obtenção de dados ou informações sobre o objeto avaliado sem que seja tomada uma atitude a favor da qualificação da aprendizagem do aluno. Ao passo que a avaliação vai além da observação e obtenção de dados para a qualificação do objeto e exige uma decisão, quer seja para conduzir a uma nova ação, quer seja para manter o curso de ação na aprendizagem, "no sentido de construir com e nos educandos conhecimentos, habilidades e hábitos que possibilitem o seu efetivo desenvolvimento" (LUCKESI, 2008, p. 71 - grifo do autor). Essa visão da avaliação corresponde ao que a maioria dos estudiosos chama de avaliação formativa, aquela que, nas palavras de Perrenoud (1991 p. 2), "ajuda o 
aluno a aprender e a se desenvolver, ou seja, que participa da regulação das aprendizagens e do desenvolvimento no sentido do projeto educativo" e que, como resume Dias (2011), "tem como principal finalidade a regulação do processo de aprendizagem do aluno".

Todavia, apontar a regulação como característica-mor da avaliação formativa não é suficiente para descrever adequadamente essa modalidade. De fato, durante as quase três décadas em que predominou, na avaliação da aprendizagem, a perspectiva neobehaviorista fundada nos trabalhos de Bloom e colaboradores (ver BLOOM et al., 1971), a função reguladora da avaliação formativa, embora presente, era de natureza estritamente retroativa, como analisou Allal (1989) em um trabalho que se tornou referência. Outra limitação daquela concepção é que todo o processo de avaliação e regulação era responsabilidade exclusiva do professor (que qualificava a realidade observada, diagnosticava os problemas e propunha soluções) e pautava-se apenas na análise dos produtos obtidos, sem considerar os processos envolvidos na atividade de aprendizagem.

Hoje, falar em regulação da aprendizagem remete a concepções oriundas do paradigma construtivista que, segundo enfatiza Rosário (2001, p. 88), coloca no primeiro plano a construção realizada pelo aprendente:

\begin{abstract}
Este marco explicativo realça o protagonismo do aluno no processo de aprendizagem, elegendo-o como o artífice, 0 verdadeiro ator do processo, uma vez que as novas aprendizagens só serão possíveis a partir dos conceitos, crenças, representações e conhecimentos que este constrói no decorrer de suas experiências prévias [...]. Nesta leitura do processo de ensino-aprendizagem, urge que a educação formal promova nos alunos estratégias de autorregulação da sua aprendizagem.
\end{abstract}

Nessa perspectiva, regulação e autorregulação andam de mãos dadas, focando os "processos cognitivos dos alunos associado aos processos de feedback, de regulação, de autoavaliação e de autorregulação das aprendizagens" (FERNANDES, 2006, p. 23). Para este autor, propiciar experiências que levem o aprendente a uma maior autonomia exige, portanto, que se use "um conjunto de recursos cognitivos e metacognitivos que ajudem a eliminar qualquer eventual distância entre as aprendizagens reais e as aprendizagens previstas ou propostas" (FERNANDES, 2006, p. 31). O aluno só se torna principal agente de sua aprendizagem ao adotar práticas sistemáticas de autorregulação e de autoavaliação.

De uma forma geral, os processos de regulação e autorregulação são objetos de estudos da psicologia cognitiva, que procura entender o funcionamento intelectual do ser humano. Para Mottier Lopez (2012, p. 7), que se interessa pela regulação da aprendizagem, isto é, a regulação desencadeada pelo próprio aprendente, falar em autorregulação é referir-se ao "processo cognitivo ou metacognitivo que tem por finalidade assegurar o controle e o ajuste das atividades cognitivas, afetivas e sociais que contribuem para a transformação dos conhecimentos e das competências do aprendente" (grifo da autora) ${ }^{3}$.

\footnotetext{
${ }^{3} \mathrm{~A}$ tradução desta e de outras citações é responsabilidade nossa.
} 
Cyr (1998), ao sintetizar e comentar diversos estudos sobre estratégias de aprendizagem de uma língua estrangeira, também insiste na relevância das capacidades metacognitivas. Ele reconhece, com base em diversas tipologias de estratégias, a importância "da autogestão, autorregulação e autoavaliação, bem como das consequências importantes destes fatores na aprendizagem" (CYR, 1998, p. 113). Citando Tardif, ele ressalta que "a metacognição constitui uma característica que diferencia os alunos em dificuldade dos alunos que não têm problemas na aprendizagem" (TARDIF 1992 apud CYR, 1998, p. 42).

$O$ processo de autorregulação, portanto, vem tendo seu papel cada vez mais evidenciado no âmbito da avaliação formativa. Rosário (apud CASTRO, 2007, p. 10) define a autorregulação como "um processo ativo em que os sujeitos estabelecem os objetivos que norteiam a sua aprendizagem, tentando monitorizar, regular e controlar as suas cognições, motivação e comportamento com o intuito de os alcançar".

Neste cenário o processo de regulação passa tanto pelo professor quanto pelo aluno. Para Mottier Lopez (2012, p. 8), "o conceito de regulação também designa os elementos do entorno social, material, simbólico que sustenta a autorregulação do aluno [...]. Estas fontes de regulação são denominadas, às vezes, de regulação externa (com relação ao aprendente e à sua autorregulação)".Cabe então ao professor propiciar os elementos de regulação externa para o desenvolvimento da regulação interna do aluno, ou seja, da autorregulação. Com efeito, a autorregulação é gerada pelos alunos, segundo Allal (1993), em situações didáticas em que eles têm uma participação efetiva. Processos autorregulatórios fazem com que os alunos elaborem novas estratégias, mobilizando conhecimentos e saber-fazer que possam contribuir "para a otimização de comportamentos condizentes com os objetivos pedagógicos visados pela escola" (ALLAL, 1993, p. 86).

Mas a autorregulação somente se exerce na medida em que há uma autoavaliação eficiente. Segundo Pillonel e Rouiller (2001, p.4), "a atitude autoavaliativa pode ser aprendida [...]. Esta aptidão reflexiva permite uma tomada de consciência de sua ação; lucidez indispensável a toda a aprendizagem significativa que somente o aluno, enquanto sujeito, pode realizar". Para esses autores, portanto, a autoavaliação deve ser tomada como objeto de aprendizagem. Lavault (2007 apud MOTTIER-LOPEZ; LAVAULT, 2008, p. 15) vê, na autorregulação associada à autoavaliação, essa mesma dupla perspectiva:

[...] a primeira, a autorregulação das aprendizagens, diz respeito à aptidão dos alunos a assumirem seus processos cognitivos e motivacionais para aprender. A segunda, a aprendizagem da autorregulação, preocupa-se com o próprio desenvolvimento dessa aptidão para exercer um maior e melhor controle sobre sua aprendizagem (grifos dos autores).

$\mathrm{Na}$ perspectiva formativa, ao desenvolver estratégias de autoavaliação e de autorregulação, o aprendente vai adquirindo condições de ser o principal agente de sua aprendizagem e passa a gerenciar seu estudo, sempre se beneficiando da tutoria mediadora do formador. Em suma, seu "poder do formando" aumenta, não sendo mais visto como "um objeto a ser transformado" (BONNIOL; VIAL, 2001, p. 318). 
Nas palavras de Rosário (2001, p. 87), "aprender requer a construção de estruturas através da reflexão e da abstração". Compreender suas características pessoais na aprendizagem da língua, identificar e adotar estratégias de aprendizagem mais apropriadas a seu estilo, reconhecer os objetivos das atividades propostas no material didático, são as ações que tornam o aluno de língua estrangeira um aprendente autônomo, que não lança apenas mão de atividades e estratégias cognitivas, mas que também é capaz de refletir sobre seu processo de aprendizagem. Por isso, os alunos autorregulados são facilmente identificados pelos professores: são "decididos, estratégicos e persistentes no seu processo de aprendizagem" (ROSÁRIO, 2001, p. 88). Nesse sentido, a "regulação está a serviço da aquisição dos saberes e dos procedimentos que permitem elaborar bons produtos [...]. A autorregulação promove o domínio de si mesmo" (BONNIOL; VIAL, 2001, p. 289). Acompanhando a autoavaliação, essa estratégia metacognitiva é imprescindível a uma aprendizagem exitosa. Em outras palavras, o "sucesso depende do que cada um sabe sobre o processo de aprendizagem e sobre si próprio enquanto aprendiz, ou seja, do seu nível de conhecimentos metacognitivos" (CARITA et al. apud CASTRO, 2007, p. 7).

É visando ao desenvolvimento dessas capacidades metacognitivas que a Faculdade de Letras Estrangeiras Modernas da Universidade Federal do Pará incluiu na sua matriz curricular a disciplina "Aprender a Aprender Línguas Estrangeiras". Essa disciplina, ofertada no primeiro bloco do currículo juntamente com a disciplina Língua Francesa I, disponibiliza aos novos aprendentes da língua conhecimentos acerca das estratégias e dos estilos de aprendizagem e, sobretudo, visa a desenvolver suas capacidades reflexivas acerca do modo como estudam a língua e monitoram suas competências comunicativas. O propósito é de ajudá-los a assumir a responsabilidade por sua aprendizagem da língua estrangeira, partindo da objetivação do seu processo de aprendizagem da LE em suas diversas dimensões (cognitivas, sociais, motivacionais e afetivas). Ao tomar seu próprio processo de aprendizagem como objeto de análise eles podem passar a entender como atuar melhor sobre sua aprendizagem, condição essa para fomentar sua autonomia (CUNHA, 2011, p. 626).

No presente estudo, veremos como essas capacidades se manifestam no discurso de alunos bem sucedidos, quando estes se expressam sobre o modo como estudam a língua.

\section{METODOLOGIA}

O estudo atual valeu-se da mesma metodologia utilizada na investigação de CUNHA (2014), no que diz respeito à geração de dados e a sua análise. Foi utilizada a grade de análise constituída no referido estudo (ver em Apêndice) para construção dos dados extraídos dos documentos produzidos pelos participantes da atual pesquisa na referida disciplina "Aprender a Aprender Línguas Estrangeiras".

A seleção dos participantes efetuou-se por meio de dados fornecidos pela secretaria da Faculdade de Letras Estrangeiras Modernas, com autorização da Direção. Entre os estudantes de língua francesa que ingressaram nos anos de 2010, 2011 e 2012, selecionamos os que atendiam aos seguintes critérios:

- terem obtidos o conceito EXC na avaliação da disciplina Língua Francesa I, no bloco de disciplinas em que também cursavam "Aprender a Aprender Línguas Estrangeiras"; 
- terem produzido pelo menos quatro documentos analíticos a respeito de sua aprendizagem, ao longo da disciplina "Aprender a Aprender Línguas Estrangeiras";

- não terem morado em país francófono ou cursado francês anteriormente a seu ingresso na Faculdade, sendo, portanto, iniciantes completos no estudo do idioma;

- terem assinado o termo de consentimento livre e esclarecido apresentado pela professora da referida disciplina que autorizava o uso dos documentos produzidos por eles para fins de pesquisa.

Foram identificados quatro estudantes que se enquadravam nesse perfil. De posse de seu nome, pudemos então constituir o corpus deste estudo com os documentos produzidos por eles ao longo da disciplina "Aprender a Aprender Línguas Estrangeiras".

Com base em uma pesquisa bibliográfica que nos permitiu ampliar os conhecimentos sobre estratégias de aprendizagem, em particular sobre as estratégias metacognitivas, foi iniciada, no âmbito dessa pesquisa documental, a análise dos documentos coletados. Ao todo, investigamos vinte e um documentos, conforme registrado no Quadro 1, a seguir, que discrimina a quantidade de documentos nas seguintes categorias: a narrativa de aprendizagem, que é um relato da aprendizagem de línguas estrangeiras anterior à aprendizagem em andamento naquele momento; os diários de aprendizagem, produzidos pelos alunos da turma para comentar seu desempenho na aprendizagem da língua alvo; o Projeto de Aprendizagem Autônoma (PAA) que consistia em um relatório final, incluindo a identificação e análise de um problema pessoal no processo de aprendizagem da língua estrangeira, com uma proposta de ação para dar conta desse obstáculo específico; documentos incluídos na rubrica Outros como: a "estrela de aprendizagem" que representava uma autoavaliação, pelo aluno, de suas capacidades de aprendizagem de uma língua estrangeira e de sua autonomia, uma descrição de seu modo pessoal de estudar francês e, finalmente, uma análise de suas motivações. As participantes da pesquisa - Joana, Andréia, Maria e Gisele são designadas por um nome fictício.

Quadro 1 - Relação dos documentos elaborados pelos sujeitos da pesquisa

\begin{tabular}{|c|c|c|c|c|c|c|}
\hline \multirow{2}{*}{ NOMES } & \multirow{2}{*}{ NARRATIVA } & \multicolumn{3}{|c|}{ DIÁRIOS } & \multirow{2}{*}{ PAA } & \multirow{2}{*}{ OUTROS } \\
\hline & & 1 & 2 & 3 & & \\
\hline JOANA & $\mathrm{X}$ & $\mathrm{X}$ & $\mathrm{X}$ & $\mathrm{X}$ & -- & $\mathrm{X}$ \\
\hline ANDRÉIA & $X$ & $\mathrm{X}$ & $\mathrm{X}$ & $\mathrm{X}$ & $X$ & $\mathrm{X}$ \\
\hline MARIA & $X$ & $\mathrm{X}$ & $\mathrm{X}$ & -- & $\mathrm{X}$ & $\mathrm{X}$ \\
\hline GISELE & $\mathrm{X}$ & $\mathrm{X}$ & $\mathrm{X}$ & -- & $\mathrm{X}$ & $\mathrm{X}$ \\
\hline
\end{tabular}

Para proceder à análise dos 21 documentos do corpus, foram identificados, neles, os trechos que continham algum comentário, direto ou indireto, sobre o uso de uma estratégia de aprendizagem. Esses trechos foram inseridos, com sua devida identificação (autor, data, tipo de documento e localização no documento), na grade constituída no estudo anterior (ver Apêndice), organizada com base na tipologia de estratégias de O'Malley e Chamot (1990). Esses autores dividem as estratégias de aprendizagem em três grupos: cognitivas, metacognitivas e socioafetivas. Ainda está incluída no quadro uma subdivisão entre as estratégias ligadas ao processo de aprendizagem (isto é, as que correspondem à intenção "aprender") e as que dizem respeito às atividades linguageiras (isto é, que correspondem à intenção 
"comunicar"), sendo relacionadas assim estratégias metacognitivas e socioafetivas à primeira categoria e estratégias cognitivas e metacognitivas à segunda.

As quatro grades preenchidas - uma para cada participante de pesquisa -, nos permitiram visualizar os processos de regulação mencionados por cada uma delas e identificar quais estratégias eram mais presentes nos diversos textos analisados. Consideramos que se estudantes, ainda iniciantes no estudo da língua, mas também na capacidade de analisar sua própria aprendizagem, comentavam uma ou outra estratégia, isso denotava a importância atribuída por elas a essas estratégias, na medida em que, em seus documentos, podiam se expressar livremente e que o foco, nesses documentos, não recaía nas estratégias de aprendizagem.

As grades individuais foram sintetizadas em duas tabelas, sendo uma para as ocorrências de estratégias relacionadas ao aprender e outra para as ocorrências relacionadas ao comunicar. Nessas tabelas, foi computado o número de ocorrências para cada tipo de estratégia e por participante, de modo a quantificarmos os resultados (em números absolutos e percentuais). Outras tabelas permitiram sintetizar os dados de modo ainda mais geral, levando-se em consideração apenas o cômputo global dos dados. Obtivemos, assim, uma visão mais ampla das ocorrências, embora essas tabelas tenham também suscitado uma análise qualitativa, como veremos a seguir, uma vez que essa análise se apoia nos próprios comentários das participantes, apresentados neste estudo sob forma de excertos.

\section{RESULTADOS}

Nessas tabelas, que passamos a analisar agora, os dados estão registrados da seguinte forma: na coluna " $S$ " (Sim) está registrado o número de ocorrências de cada estratégia mencionada pelas alunas participantes da pesquisa como tendo sido usada com êxito; na coluna "N" (Não) o número das que são apontadas como não tendo dado resultados; e, na coluna "T" (Talvez), o número das que aparecem nos documentos analisados como algo que as estudantes ainda pretendiam fazer. $\mathrm{O}$ símbolo "--" indica as estratégias para as quais não se encontrou ocorrência de nenhum tipo nos documentos analisados.

\subsection{Estratégias voltadas à aprendizagem}

As estratégias voltadas às atividades de aprender, que são computadas na Tabela 1, a seguir, estão divididas entre estratégias metacognitivas e estratégias socioafetivas. As metacognitivas têm como objetivo a reflexão sobre o processo de aprendizagem em si e sobre os elementos que o favorecem. Na tipologia de O'Malley e Chamot (1990), este conjunto envolve estratégias como antecipação e planejamento, autoavaliação, autogestão e autoavaliação da aprendizagem. As estratégias socioafetivas, por sua vez, estão voltadas às relações interpessoais dos aprendentes com falantes da língua alvo (nativos ou não) e ao gerenciamento da dimensão afetiva da aprendizagem com a finalidade de se apropriar da língua estrangeira. Esta última categoria compreende estratégias de cooperação, controle das emoções e autorreforço. 
Tabela 1 -Distribuição das estratégias voltadas à aprendizagem por participante

\begin{tabular}{|c|c|c|c|c|c|c|c|c|c|c|c|c|}
\hline & \multicolumn{3}{|c|}{ JOANA } & \multicolumn{3}{|c|}{ ANDRÉIA } & \multicolumn{3}{|c|}{ MARIA } & \multicolumn{3}{|c|}{ GISELE } \\
\hline & $\mathrm{S}$ & $\mathrm{N}$ & $\mathrm{T}$ & $\mathrm{S}$ & $\mathrm{N}$ & $\mathrm{T}$ & $\mathrm{S}$ & $\mathrm{N}$ & $\mathrm{T}$ & $\mathrm{S}$ & $\mathrm{N}$ & $\mathrm{T}$ \\
\hline \multicolumn{13}{|c|}{ ESTRATÉGIAS METACOGNITIVAS } \\
\hline Antecip./Planej. & 1 & -- & 4 & -- & 1 & 2 & -- & -- & 7 & -- & -- & -- \\
\hline Autogestão & 4 & -- & -- & 3 & 3 & 1 & 3 & -- & -- & 2 & -- & -- \\
\hline Autoavaliação & 4 & 5 & 2 & 4 & 5 & 6 & 9 & 7 & 3 & 2 & 4 & -- \\
\hline Autorregulação & 2 & -- & -- & 3 & -- & -- & 3 & -- & -- & 2 & 1 & -- \\
\hline Subtotal 1 & 11 & 5 & 6 & 10 & 9 & 9 & 15 & 7 & 10 & 6 & 5 & 0 \\
\hline \multicolumn{13}{|c|}{ ESTRATÉGIAS SOCIOAFETIVAS } \\
\hline Cooperação & 2 & -- & -- & 2 & -- & -- & 4 & -- & -- & 9 & -- & -- \\
\hline Controle emoções & 1 & -- & -- & 4 & 9 & -- & 1 & 1 & -- & 2 & -- & -- \\
\hline Autorreforço & 1 & -- & 2 & 1 & 1 & 3 & 3 & -- & 2 & 2 & -- & 1 \\
\hline Subtotal 2 & 4 & 0 & 2 & 7 & 10 & 3 & 8 & 1 & 2 & 13 & 0 & 1 \\
\hline
\end{tabular}

Ao observarmos a Tabela 1, percebemos que, excetuando-se as estratégias de antecipação/planejamento que não aparecem na coluna "S" de três das participantes (Andréia, Maria e Gisele), todas as outras estratégias, quer metacognitivas, quer socioafetivas, estão presentes. Isso significa que são mencionadas positivamente por todas as participantes quando estas comentam seu processo de aprendizagem.

Para apreendermos de modo mais global a distribuição dessas ocorrências, indicamos, na Tabela 2, a soma das diferentes categorias, em números absolutos e percentuais:

Tabela 2 - Total das ocorrências de estratégias voltadas à aprendizagem

\begin{tabular}{c|c|c|c|c}
\cline { 2 - 5 } & $\begin{array}{c}\text { Estratégias } \\
\text { metacognitivas }\end{array}$ & $\begin{array}{c}\text { Estratégias } \\
\text { socioafetivas }\end{array}$ & Total & $\begin{array}{c}\text { Total } \\
\text { (Percentual) }\end{array}$ \\
\hline $\mathbf{S}$ & 42 & 32 & $\mathbf{7 4}$ & 51 \\
\hline $\mathbf{N}$ & 26 & 11 & $\mathbf{3 7}$ & 26 \\
\hline $\mathbf{T}$ & 25 & 8 & $\mathbf{3 3}$ & 23 \\
\hline Total & 93 & 51 & $\mathbf{1 4 4}$ & 100 \\
\hline
\end{tabular}

Tanto as estratégias metacognitivas, quanto as socioafetivas são mencionadas positivamente em um número elevado de vezes, em relação às outras categorias (as incertas na coluna "T" e as negativas na coluna "N"): 42 ocorrências positivas em um total de 93 estratégias metacognitivas mencionadas e 32 em um total de 51 estratégias socioafetivas. Mais da metade dos comentários feitos pelas participantes indica, portanto, o uso bem sucedido dessas duas categorias de estratégias. Entretanto, os $49 \%$ de menções restantes, correspondendo a seu uso incerto ou malsucedido, não deixa de ser positivo, pois acabam expressando a forte preocupação das participantes com seu processo de aprendizagem, como veremos mais adiante. Observaremos agora mais detalhadamente o que se percebe em cada categoria de estratégias.

No que diz respeito às estratégias metacognitivas utilizadas pelas participantes em prol do processo "aprender", destacam-se as de autogestão, autoavaliação e autorregulação. Os excertos (1) a (3), oriundos dos documentos do corpus, ilustram respectivamente o uso dessas estratégias, sendo que o (2) apresenta tanto a de autoavaliação quanto a de autogestão: 
(1) "[...] determinar, durante a semana, meu tempo de estudo ou parar todos os dias uma ou duas horas para estudar. Eu já faço isso [...]" (Maria - Outros -2012).

(2) "Não tive grandes dificuldades com os assuntos propostos, mas ainda assim procurei adicionar o francês em minha rotina diária de imediato" (Gisele - Diário 1 - 05/2012).

(3) "A primeira coisa que fiz foi reorganizar meu horário de aprendizado: precisei sacrificar os filmes franceses de terça e sexta para ampliar o horário de revisão de francês" (Joana - Diário 3 - 06/2010).

Esse fato parece corroborar a hipótese de que aprendentes bem sucedidos conseguem identificar seus problemas (aqui, problemas de aprendizagem) e encontram soluções adaptadas para eles, tentando maximizar sua aprendizagem, uma vez que essas operações envolvem gestão do tempo e das atividades, bem como avaliação e regulação, pelo próprio aprendente, do modo como ele organiza seu estudo.

Poderia parecer paradoxal, nessas condições, que, entre as ocorrências inseridas na coluna " $N$ ", predominem nitidamente as que se referem à autoavaliação (21 ocorrências em 26). Podemos considerar, todavia, que essas autoavaliações negativas manifestam a clareza das aprendentes em relação à qualidade e à pertinência de seu trabalho, como se pode perceber nos excertos (4) a (7):

(4) "[...] o cansaço impede uma boa concentração em aprendizagem de línguas" (Joana - Diário 2 - 03/2004).

(5) 'Plano de estudos com 'destinação' de tempo definitivamente para mim não dá certo!" (Andréia - Diário 3 - 05/2010).

(6) "[...] o mês em que, na minha opinião, eu mais relaxei e fui levando "com a barriga"' (Maria - Diário 1- 04/2012).

(7) "Procurei exercícios na internet que me ajudassem a fixar, mas não renderam grandes resultados. Cheguei à conclusão de que há algo de errado com o modo que estudo, mas ainda não consegui identificar o que há de errado exatamente" (Gisele - Diário 2 06/2012).

Ao avaliar aquilo que não consideram positivo (falta de concentração, determinação prévia do tempo dedicado a cada atividade, falta de seriedade no estudo), as participantes estão, na verdade, mostrando que tomaram consciência dos obstáculos e que conseguem analisá-los sem condescendência. Mencionam inclusive tentativas de regulação que possam ter experimentado, como em (7), quando Gisele relata sua frustração com os exercícios da internet. Esta última avaliação, ainda que imprecisa, já que notifica apenas "algo errado", é o primeiro passo para superar dificuldades. O fato de Gisele especificar que "ainda não" identificou o que não deu certo sinaliza sua intenção de chegar a uma conclusão mais produtiva.

Também chama a atenção, na Tabela 2, o número relativamente elevado de ocorrências inseridas na coluna "Talvez": 25 ocorrências em um total de 93 (ou seja, $27 \%$ das estratégias metacognitivas mencionadas) são comentários em que as participantes identificam uma das estratégias que pretendem passar a usar. Nos trechos (8) a (12) abaixo, as participantes mencionam, por exemplo, estratégias de 
antecipação e planejamento em (8) e (9), de autogestão em (10), de autoavaliação em (11), de autorregulação em (12):

(8) "Vou fazer um horário, uma agenda, para saber o momento de ler, de assistir um vídeo... E assim sistematizar meus estudos" (Andréia - Outro $-03 / 2010)$.

(9) "Com o tempo será necessário determinar, durante a semana, meu tempo de estudo ou parar todos os dias uma ou duas horas para estudar" (Maria - Outro - 2012).

(10) "Talvez nos próximos módulos seja mais fácil definir o plano de estudos" (Andréia - Diário 2 - 04/2010).

(11) "Acredito que venho estudando a língua francesa de forma contida, talvez precise melhorar o meu desempenho em sala de aula" (Maria Outros - 2012).

(12) "Depois de inúmeras tentativas de estabelecer tempo para cada atividade todas sem sucesso, percebi que a finalidade do plano de estudos não era exatamente o tempo, mas, definir estratégias, levando em consideração o processo individual de aprendizado e gerenciamento do mesmo, não necessariamente organizado por um relógio, mas autorregulada pelo próprio aluno" (Andréia - PAA - 06/2010).

No que diz respeito às estratégias socioafetivas (de cooperação, controle das emoções e autorreforço), todas são mencionadas positivamente pelas participantes, excetuando-se a de autorreforço que é omitida por Maria. Todas essas estratégias têm um número particularmente maior de menções a um uso bem sucedido (32 na coluna "S") do que de inserções na coluna "T" (8 no total). Ressalta-se que, entre as participantes, apenas Andréia faz repetidas menções negativas às estratégias socioafetivas (10 em um total de 11), indicando, principalmente, ter dificuldades em gerenciar suas emoções, como ilustram os trechos (13) e (14) abaixo:

(13) "O problema sou eu. Se eu pudesse não falar, era melhor, mas não existe isso, eu sei!" (Andréia - Diário 1 - 04/2010).

(14) "Senti uma certa angústia. [...] Não consigo tirar dúvidas ou fazer perguntas" (Andréia - Diário 2 - 05/2010).

No que diz respeito à estratégia de cooperação, citada positivamente por todas as estudantes, observamos que várias pessoas são mencionadas, de professores a amigos e familiares, como auxiliadores na interação com a aprendizagem da língua alvo. Este fato é exemplificado nos trechos (15) e (16):

(15) "[...] falo francês muito melhor [...] quando estou com alguém da minha família" (Maria - Outros - 2012).

(16) "[...] o feedback positivo que recebo de meus colegas [...] me incentiva a continuar tentando comunicar na língua alvo [...]" (Gisele - Diário 1 - 05/2012).

Emoções negativas como medo da exposição em publico, sentimento de insegurança e até pânico estão presentes no início dos relatos, como já exemplificado em (13) e (14). Mas todas as participantes, inclusive Andréia, 
demonstram ter progredido nesse aspecto e estar conseguido controlar tais emoções, como se vê em (17) e (18):

(17) "Estou evoluindo a respeito do nervosismo ao falar... e já consigo tirar dúvidas e fazer as tarefas orais sem precisar me preparar psicologicamente. Estou encontrando o ponto de estabilidade emocional e avanço nos estudos" (Andréia - Diário 3 - 05/2010).

(18) "[...] perdi grande parte do receio que tinha em me expressar em francês, o que me deixou ainda mais motivada a praticar em casa e a participar mais ativamente das aulas" (Gisele - Diário 1 - 05/2012).

Finalmente as aprendentes usam, em diversos momentos, a estratégia de autorreforço, conforme os excertos (19) e (20) abaixo. A motivação também aparece como um elemento importante para todos os sujeitos.

(19) "Estou muito entusiasmada, sei que vou aprender muito. Isso é maravilhoso" (Andréia - Diário 1 - 03/2010).

(20) "Sei que encontrarei dificuldades ainda maiores pela frente e ao decorrer do curso, mas pretendo lidar bem com os problemas futuros [...] cada dia mais ser motivada a provações futuras." (Maria - PAA - 07/2012).

Apesar do medo inicial de falar a língua estrangeira em público, as participantes souberam recorrer a interações diversas para buscar uma segurança maior com relação à aprendizagem da língua, além de praticarem sozinhas a língua alvo, inclusive Andréia, que apresentava uma autocrítica bastante negativa com relação à sua aprendizagem.

Considerando ambos os grupos de estratégias para aprender (metacognitivas e socioafetivas), encontramos um número total de ocorrências positivas (74 na coluna "S") bem maior do que de ocorrências negativas (37 na coluna "N"), além de as estudantes indicarem um bom número de estratégias que pretendiam incorporar à sua prática (33 na coluna "T").A análise dos diversos documentos produzidos por elas ao longo de seu primeiro semestre de aprendizagem mostra que usaram um amplo leque de estratégias, focando nas que estão mais condizentes com seu próprio estilo de aprendizagem. Embora todas tenham tendência a se autoavaliar de forma exigente, apresentaram no decorrer do semestre uma maior reflexão sobre a aprendizagem da língua e, sobretudo, um autoconhecimento mais aprofundado.

\subsection{Estratégias voltadas às atividades linguageiras}

$\mathrm{Na}$ Tabela 3, a seguir, analisamos as atividades voltadas para o processo "comunicar". Na primeira parte da tabela, assim como na anterior, estão reunidas as estratégias metacognitivas voltadas, desta vez, às atividades linguageiras. São as seguintes estratégias, segundo Cyr (1998): a autoavaliação, que corresponde às reflexões que as aprendentes desenvolveram com relação à comunicação oral ou escrita na língua estrangeira. Na autorregulação encontramos as ações adotadas por elas com o objetivo de incrementar suas competências linguísticas através de autocorreções e nas estratégias de atenção, geral e seletiva, registram-se as ações que permitem uma melhor concentração nas atividades comunicativas. 
$\mathrm{Na}$ segunda parte da tabela, situam-se as estratégias cognitivas, as quais implicam "uma interação entre o aprendente e objeto de estudo, uma manipulação física ou mental da língua alvo e a aplicação de técnicas específicas tendo em vista a resolução de um problema [...]" (CYR, 1998, p. 63). Veremos que, neste levantamento, são as estratégias que apresentam um maior número de menções de caráter positivo, sendo consideradas práticas bem sucedidas pelas participantes da pesquisa. Entre elas estão a repetição, ou prática da língua na definição de O'Malley e Chamot (1990), que envolve todas as ocasiões de usar a língua alvo, estando em uma situação de exercício, de comunicação autêntica ou de diálogo consigo mesmo. $\mathrm{Na}$ pesquisa documental/uso de recursos, destaca-se o recurso a documentos na língua alvo, como livros, filmes ou materiais didáticos extras em língua estrangeira. Para classificar e reagrupar elementos linguísticos o aprendente adota critérios pessoais para dispor esses elementos de modo a facilitar a memorização e recuperação dessas informações. A tradução envolve a comparação da língua alvo com outras línguas conhecidas para facilitar a compreensão lexical ou a apreensão dos funcionamentos morfossintáticos, por exemplo. A tomada de notas consiste nas anotações e observações de informações na língua estrangeira. Na elaboração o aprendente estabelece relações entre o conhecimento recente e o conhecimento anterior da língua alvo ou de outras línguas. O resumo, mental ou escrito, é uma técnica que pode ser encorajada pelo próprio professor ao sintetizar, por exemplo, os recursos linguísticos trabalhados em classe.

Tabela 3 - Distribuição das estratégias voltadas às atividades linguageiras por participante

\begin{tabular}{|c|c|c|c|c|c|c|c|c|c|c|c|c|}
\hline & \multicolumn{3}{|c|}{ Joana } & \multicolumn{3}{|c|}{ Andréia } & \multicolumn{3}{|c|}{ Maria } & \multicolumn{3}{|c|}{ Gisele } \\
\hline & $\mathrm{S}$ & $\mathrm{N}$ & $\mathrm{T}$ & $\mathrm{S}$ & $\mathrm{N}$ & $\mathrm{T}$ & $\mathrm{S}$ & $\mathrm{N}$ & $\mathrm{T}$ & $\mathrm{S}$ & $\mathrm{N}$ & $\mathrm{T}$ \\
\hline \multicolumn{13}{|c|}{ ESTRATÉGIAS METACOGNITIVAS } \\
\hline Autoavaliação & 8 & - & -- & 13 & -- & -- & 8 & - & - & 13 & -- & -- \\
\hline Autorregulação & 3 & 1 & 1 & 1 & -- & -- & 3 & -- & -- & 5 & 1 & -- \\
\hline $\begin{array}{l}\text { Atenção geral e } \\
\text { seletiva }\end{array}$ & 1 & - & 1 & 1 & -- & -- & 2 & -- & - & 1 & -- & -- \\
\hline Subtotal 1 & 12 & 1 & 2 & 15 & 0 & 0 & 13 & 0 & 0 & 19 & 1 & 0 \\
\hline \multicolumn{13}{|c|}{ ESTRATÉGIAS COGNITIVAS } \\
\hline Repetição & 7 & 1 & 1 & 8 & -- & -- & 6 & - & 1 & 6 & 2 & -- \\
\hline $\begin{array}{c}\text { Pesquisa } \\
\text { doc./Recursos }\end{array}$ & 6 & -- & -- & 2 & -- & -- & 6 & - & - & 2 & -- & -- \\
\hline Classificar/reagrupar & 4 & - & -- & 1 & -- & -- & 1 & - & - & 1 & -- & -- \\
\hline Tradução & 5 & -- & -- & -- & -- & -- & -- & 2 & -- & -- & - & -- \\
\hline Tomada de notas & 1 & -- & -- & -- & -- & -- & 1 & -- & -- & -- & -- & -- \\
\hline Elaboração & 1 & -- & -- & -- & -- & -- & -- & -- & - & -- & -- & -- \\
\hline Resumo & - & -- & -- & 1 & -- & -- & -- & -- & - & -- & -- & -- \\
\hline Subtotal 2 & 24 & 1 & 1 & 12 & 0 & 0 & 14 & 2 & 1 & 9 & 2 & 0 \\
\hline
\end{tabular}

$\mathrm{Na}$ Tabela 3, observamos que todas as estratégias metacognitivas são objeto de comentário positivo por parte das participantes. Entretanto nem todas as estratégias cognitivas, cuja variedade é maior, são mencionadas por todas elas. 


\begin{tabular}{c|c|c|c|c}
\multirow{2}{*}{ Tabela $4-$ Total das ocorrências de estratégias voltadas à comunicação } \\
\cline { 2 - 5 } & $\begin{array}{c}\text { Estratégias } \\
\text { metacognitivas }\end{array}$ & $\begin{array}{c}\text { Estratégias } \\
\text { cognitivas }\end{array}$ & Total & $\begin{array}{c}\text { Total } \\
\text { (Percentual) }\end{array}$ \\
\hline $\mathbf{S}$ & 59 & 59 & $\mathbf{1 1 8}$ & 91 \\
\hline $\mathbf{N}$ & 2 & 5 & $\mathbf{7}$ & 6 \\
\hline $\mathbf{T}$ & 2 & 2 & $\mathbf{4}$ & 3 \\
\hline Total & 93 & 51 & $\mathbf{1 2 9}$ & 100 \\
\hline
\end{tabular}

Como se vê na Tabela 4, que sintetiza esses dados em números absolutos e percentuais, a utilização bem-sucedida do conjunto de estratégias voltadas para as atividades de comunicação predomina fortemente, com $91 \%$ das ocorrências. A menção negativa ao conjunto das estratégias (coluno "N") só representa $6 \%$ do total das ocorrências, enquanto aquelas cujo uso ainda é incerto (coluna "T") representam apenas 3\%.

No tocante às estratégias metacognitivas, observa-se, na Tabela 3, que além de terem um olhar crítico sobre sua forma de estudar, como vimos na seção anterior, as participantes da pesquisa também produzem numerosas avaliações sobre o seu desempenho nas atividades linguageiras. Muitas dessas autoavaliações são bastantes críticas, como em (21), (22) e (23):

(21) "Minha pronúncia é questão de dar medo de tão ruim que está" (Joana - Diário 2- 04/2010).

(22) "Percebo que tenho mais facilidade na escrita que na oralidade, devido a essa falta de prática em sala de aula" (Maria - Outros 2012).

(23) "Troca, ausência ou esquecimento de letras é algo recorrente para mim, não saber como escrever certas palavras cotidianas também [...]. Escrever um pequeno bilhete contando meus planos é uma tarefa hercúlea, nunca sei se estou escrevendo 0 verbo corretamente ou se algo deve ser mudado" (Gisele - PAA 07/2012).

Mas a percepção dos problemas vem acompanhada por muitas ocorrências de autorregulação, nas quais as aprendentes mencionam as ações adotadas para suprir as lacunas que perceberam, como em (24) e (25):

(24) "[...] resolvi retomar de verdade as tabelinhas de decorar verbos e grudei nas paredes, assim como fiz com as matérias do ensino médio" (Joana Diário 2 - 04/2010).

(25) "[...] a fim de solucionar meus problemas, continuei a resolver os exercícios do cahier e me concentrei em escrever pequenos bilhetes marcando encontros com pessoas imaginárias" (Gisele - Diário 2 06/2012).

As estratégias de atenção geral e seletiva também são mencionadas pelos aprendentes, como modo de incrementar seu desempenho, o que os trechos (26) e (27) exemplificam:

(26) "Em sala de aula tentei não perder a atenção... tentei... acho que estou conseguindo!" (Andréia - Diário 3 - 05/2010). 
(27) "Procuro me manter sempre focada e atenta em sala de aula" (Maria Outros -2012).

Pouquíssimas são as ocorrências em que as participantes constatam que o uso de uma estratégia metacognitiva não foi bem sucedido (apenas 2 na coluna "N" Tabela 4) ou que deveria ser experimentado (2 também na coluna "T"), mas ainda assim, essas ocorrências sinalizam que houve, de sua parte, tentativas de autorregulação para superar dificuldades, como em (28), no primeiro caso, e em (29), no segundo:

(28) "Preciso também melhorar minha escrita. Recentemente comecei a transcrever diálogos, mas ainda sinto que não é o suficiente" (Gisele Outros - 04/2012).

(29) "[...] estou tentando sanar essa minha frustração de surdez aguda lendo o que está escrito" (Joana - Diário 2 - 04/2010).

$\mathrm{Na}$ segunda parte da Tabela 3 , reservada às estratégias cognitivas, chama a atenção o fato de que apenas três tipos de estratégias são mencionados por todas as participantes. As outras são praticadas esporadicamente por uma ou outra. Entre essas três, a repetição ou prática da língua é a que concentra o maior número de ocorrências realizadas com êxito (27). Cada aprendente usa esta estratégia, que está entre as mais conhecidas, conforme seu estilo de aprendizagem, como podemos ver nos trechos abaixo (30) a (33):

(30) "Em casa também treino o ritmo e tento formar frases para unir as palavras" (Joana - Diário 2 - 04/2010).

(31) "Eu leio, escrevo e construo diálogos... Falo em voz alta..." (Andréia Diário 3 -06/2010).

(32) "[...] vendo filmes, lendo livros - mesmo que ainda seja muito difícil conseguir entendê-los - e principalmente, falando" (Maria - Diário 2 05/2012).

(33) "Todos os dias eu refazia os exercícios do manual e ficava repetindo os verbos être e avoir mentalmente sempre que tinha oportunidade" (Gisele - Diário 1 -05/2012).

Essa estratégia é também praticamente a única que tenha registrado comentários negativos (apenas 3 ocorrências), como em (34), sinalizando, assim mesmo, esforços da Gisele para sobrepor dificuldades:

(34) "Nem mesmo tentar escrever/formular frases no passado tem me ajudado a absorver, eu sempre erro verbo auxiliar ou conjugação do verbo principal..." (Gisele - Diário 2 - 06/2012).

A pesquisa documental e o uso de recursos é a segunda estratégia mais utilizada, exemplificada nos comentários abaixo:

(35) “Em casa escuto algumas rádios francesas pelo início do dia e a tendência é passar o dia todo escutando quando puder por dois dias" (Joana - Diário 2 - 04/2010). 
(36) "Não tenho vergonha de falar que utilizava a duvidosa ferramenta do Google Tradutor" (Maria - PAA - 07/2012).

Finalmente, a estratégia que vem em terceira posição das empregadas por todas as participantes de pesquisa é a classificação/reagrupamento, referida nos seguintes comentários:

(37) "Fiz também outra das minhas tabelinhas, desta vez só com o passé composé. No momento, tem apenas os verbos vistos nas unidades passadas" (Joana - Diário 3 - 06/2010).

(38) "Procurei todas as palavras que tinham consoantes juntas [...] e as escrevi num bloquinho, procurando a cada dia me familiarizar com elas, sendo faladas da forma correta" (Maria - PAA - 07/2012).

A tradução, estratégia mencionada apenas por Joana e Maria, é registrada positivamente pela primeira, que já possui experiência na aprendizagem de três outras línguas (excerto 39). No caso de Maria, ao contrário, a influência das outras línguas aprendidas (inglês e, sobretudo, espanhol) interfere negativamente na aprendizagem do francês, segundo seus relatos. Devido ao que ela chama de "atitude hispânica", sua tendência é usar a pronúncia em espanhol.

(39) "Esta semana começamos a ver o passé composé, [...] que lembra o passado alemão - a diferença é que o verbo não vai para o final. Mas o sentido parece ser o mesmo: mudança de estado e deslocamento com être; demais verbos de ação com avoir" (Joana - Diário 3 - 05/2010).

As outras estratégias, como tomada de notas, elaboração e resumo praticamente não aparecem nos documentos analisados, mas as poucas menções registradas são todas positivas. Ninguém faz referência negativa a essas estratégias, nem, tampouco, demonstra intenção de experimentá-las. Essa aparente indiferença provavelmente se explique por essas estratégias não serem de uso comum na cultura escolar brasileira.

A análise dos dados evidencia a clara presença de processos de regulação, quando as participantes da pesquisa mostram fazer grande uso de todas as estratégias metacognitivas nas atividades de linguagem, especialmente a autoavaliação e a autorregulação. $E$, embora tenham tendência a se autoavaliar severamente (ou talvez por isso mesmo), elas procuram autorregular suas atividades linguageiras, valendo-se, sobretudo de estratégias cognitivas mais tradicionais, tais como a repetição, a pesquisa documental e uso de recursos, a classificação e o reagrupamento. Procedendo assim, foram aprovadas com o conceito máximo, que não costuma ser atribuído facilmente pelos professores da licenciatura de francês. Veremos agora em que este comportamento se distingue daquele observado nos estudantes desistentes de um estudo anterior.

\subsection{Análise comparativa do uso das estratégias}


Ao compararmos os resultados do estudo anterior, realizado junto a um público de alunos desistentes ${ }^{4}$ (AUTOR, 2014) com os do atual - ambos sintetizados na Tabela 5, abaixo -, algumas constatações se impõem. Em nível global, se não levarmos em conta a distinção entre diferentes categorias de estratégias (voltadas para o aprender ou para o comunicar) e de respostas (positivas, negativas ou incertas), observamos que o total geral de ocorrências mencionadas nos documentos analisados é praticamente uma vez e meia maior nos documentos redigidos pelas aprendentes bem-sucedidas do que nos do grupo de estudantes desistentes (273 contra 189). Isso parece significar que alunos bem-sucedidos conseguem objetivar mais suas atividades cognitivas, quer estas se exerçam no modo como aprendem, quer sejam ligadas ao modo como comunicam na língua estrangeira.

Outra observação geral que se pode fazer, considerando, desta vez, as duas categorias de estratégias, é que a diferença no número total de estratégias relativas ao aprender, entre os dois públicos pesquisados, se deve ao número de menções positivas das participantes bem-sucedidas (74 contra 46), as respostas negativas ou incertas estando equivalentes para os dois públicos.

Os números se distanciam ainda mais no âmbito de estratégias relativas ao comunicar, quando o número de ocorrências na coluna "Sim" chega a ser duas vezes e meia maior no grupo das aprendentes bem sucedidas do que no dos estudantes desistentes (118 contra 45).

Tabela 5 - Número total de ocorrências nos dois estudos

\begin{tabular}{|c|c|c|c|c|c|c|}
\cline { 2 - 7 } \multicolumn{1}{c|}{} & \multicolumn{2}{c|}{$\begin{array}{c}\text { Estudo anterior realizado junto a } \\
\text { aprendentes desistentes }\end{array}$} & \multicolumn{2}{|c|}{$\begin{array}{c}\text { Estudo atual realizado junto a } \\
\text { aprendentes bem sucedidos }\end{array}$} \\
\cline { 2 - 7 } & $\begin{array}{c}\text { Estratégias } \\
\text { relativas } \\
\text { ao } \\
\text { aprender }\end{array}$ & $\begin{array}{c}\text { Estratégias } \\
\text { relativas } \\
\text { ao } \\
\text { comunicar }\end{array}$ & $\begin{array}{c}\text { Subtotal } \\
1\end{array}$ & $\begin{array}{c}\text { Estratégias } \\
\text { relativas } \\
\text { ao } \\
\text { aprender }\end{array}$ & $\begin{array}{c}\text { Estratégias } \\
\text { relativas } \\
\text { ao } \\
\text { comunicar }\end{array}$ & Subtotal 2 \\
\hline S & 46 & 45 & 91 & 74 & 118 & 192 \\
\hline $\mathrm{N}$ & 38 & 24 & 62 & 37 & 7 & 44 \\
\hline T & 35 & 1 & 36 & 33 & 4 & 37 \\
\hline Total & 119 & 70 & $\mathbf{1 8 9}$ & 144 & 129 & $\mathbf{2 7 3}$ \\
\hline
\end{tabular}

Percebe-se, ao longo da análise, que, ao lançar mão de um grande número de estratégias voltadas para a atividade linguageira, as participantes da pesquisa 0 fazem de forma articulada com uma reflexão sobre as estratégias voltadas para a aprendizagem: muitas já aprovadas por elas, mas outras incluídas na dinâmica da regulação como procedimentos que iriam experimentar e/ou que experimentaram e não aprovaram (determinar ou não um tempo para diferentes tipos de atividades, por

\footnotetext{
${ }^{4}$ No estudo anterior, analisou-se, com a mesma metodologia do que no presente estudo, o modo como quatro estudantes, que desistiram da Licenciatura em Língua Francesa no final do primeiro semestre letivo, regulavam tanto suas atividades de aprendizagem quanto as de comunicação. Concluiu-se que "os sujeitos que apresentam dificuldade em analisar e direcionar adequadamente seu processo de aprendizagem, apoiando-se mais nas interações com pares mais adiantados ou no que definimos como 'pensamentos mágicos', também mostram ter grande dificuldade em escolher atividades cognitivas favoráveis à aprendizagem da língua. Percebe-se que o fato de não dominar as ações que poderiam dar direcionamento às atividades de aprendizagem traduz-se na incapacidade de regular as atividades linguageiras e, de forma certamente interligada, na falta de sentido das estratégias de uso da língua. Estas aparecem como completamente dissociadas dos objetivos comunicativos visados na aprendizagem e no material pedagógico utilizado" (CUNHA, 2014, p. 144).
} 
exemplo). Essa evidente preocupação com o modo como estudam, que acompanha uma avaliação e regulação da eficiência das estratégias usadas, corrobora a hipótese segundo a qual os aprendentes bem sucedidos não são os que não têm dificuldades na aprendizagem da língua, mas os que conseguem analisar essas dificuldades e regular sua aprendizagem e, de forma interligada, suas atividades linguageiras.

Com essa comparação dos dados obtidos junto aos dois tipos de público, depreendemos algumas ações que nos parecem favorecer a autorregulação e que, portanto, caracterizam um aprendente como tendo se tornado o principal agente de sua aprendizagem:

- experimentar grande variedade de estratégias de aprendizagem (metacognitivas, cognitivas e socioafetivas), ainda que seja para perceber depois que não foram muito produtivas;

- explorar tanto as estratégias de aprendizagem quanto as de comunicação, preocupando-se com a qualidade da comunicação, bem como com as atividades subjacentes a elas;

- praticar estratégias de autorregulação e autoavaliação (autoavaliar-se sem se autorregular, como mostrou o estudo anterior, de nada adianta);

- gerir sua aprendizagem de acordo com seu próprio estilo como aprendente, percebendo, assim, o que mais se adequa a seu jeito pessoal de ser e de aprender;

- desenvolver uma atitude participativa diante da aprendizagem e procurar ter senso crítico;

- buscar autoconhecimento enquanto aprendente.

A disciplina "Aprender a Aprender Línguas Estrangeiras" certamente contribui para que essas práticas sejam entendidas e experimentadas pelos estudantes, mas possivelmente não seja suficiente, considerando o pequeno número de sujeitos muito bem sucedidos que conseguimos encontrar em três turmas para realizar nosso estudo.

\section{CONSIDERAÇÕES FINAIS}

Ao longo do presente estudo, vimos que as aprendentes, apesar de sua tendência em se autoavaliarem negativamente, reconhecem seus pontos fracos e fortes e exploram os recursos disponíveis para aprender a língua francesa. Recorrem com frequência à estratégia de autorregulação, tanto no âmbito do aprender quanto no âmbito do comunicar, e gerenciam sua aprendizagem de acordo com seus modos individuais de aprender, mostrando ter adquirido certa clareza em relação a seus procedimentos como aprendentes. Acreditamos que essa tomada de consciência tenha sido um importante fator para o êxito na aprendizagem da língua alvo.

Entretanto, a comparação com os dados do estudo anterior nos permitiu evidenciar outro fator importante, que é a interligação entre estratégias de aprendizagem e estratégias de comunicação: estratégias de aprendizagem não se exercem no absoluto, e sim, precisam ter objetos bem definidos e serem confirmadas no embate com a comunicação. Alunos bem sucedidos usam um número maior de estratégias do que os que têm dificuldades, mas, possivelmente, avaliam e regulam suas estratégias de aprendizagem em função das informações obtidas no uso de estratégias voltadas para a comunicação e vice-versa. Preocuparse com o modo como se aprende só tem efeito positivo na medida em que o 
aprender é corretamente direcionado em relação às exigências do comunicar (o que se aprende) e a preocupação com o êxito na comunicação deve levar a uma análise coerente do modo de aprender.

Por isso, embora os resultados desta investigação reforcem a importância dos processos de autorregulação e autoavaliação em vista de uma aprendizagem da língua estrangeira coroada de êxito, também deixam mais claro que possuir informações acerca das estratégias e estilos de aprendizagem não é o suficiente para se desenvolver capacidades de autoavaliação e autorregulação. A disciplina "Aprender a Aprender Línguas Estrangeiras" vem propondo aos aprendentes uma reflexão sobre as variáveis inerentes à aprendizagem, mas para a maioria dos alunos (já que as quatro participantes do estudo constituem exceções entre os alunos iniciantes), essa reflexão precisa ser contextualizada, mais sistematicamente e mais concretamente, nas aulas de línguas, diante dos problemas de aprendizagem concretos do momento. Desta forma, possivelmente, é que se dará uma maior articulação das estratégias voltadas para a aprendizagem com as voltadas para a comunicação.

Concluímos este estudo reafirmando a importância de se desenvolver capacidades de objetivação e regulação para que os aprendentes possam tornar-se, de fato, agentes de sua aprendizagem, mas sugerimos novas pesquisas com relação ao papel do professor e à regulação externa no desenvolvimento dessas competências de autorregulação nos aprendentes de línguas estrangeiras.

\begin{abstract}
In continuation of a previous study on the use of strategies by French language undergraduate drop-out students, we analyze reflective documents produced in the subject "Learning to Learn Foreign Languages" by students who have achieved excellent level in language classes. In these productions, they were identified and analyzed as occurrences of strategies linked to learning activities ("Study" plan), as well as those related to language activities ("communication" plan). The comparison with the previous results showed that, besides using in a significantly higher number of strategies, successful students better articulate their study efforts in their communication process, evaluating and regulating as a strategy aimed at learning in function of information obtained without the use of a communication strategy and vice versa, with a positive impact on their language proficiency. A research has thus allowed us to understand actions that seem to favor the learners' self-regulation.
\end{abstract}

KEYWORDS: Language Learning Strategies; Formative assessment; Self-regulation.

\title{
Referências:
}

ALLAL, Linda (1993). Régulations métacognitives: Quelle place pour l'élève dans l'évaluation formative? In: ALLAL, Linda; BAIN, Daniel; PERRENOUD, Philippe 
(org.). Évaluation formative et didactique du français. Paris: Delachaux \& Niestlé. p. 81-98.

(1989). Stratégies d'évaluation formative: conceptions psycho-pédagogiques et modalités d'application. In: ALLAL, Linda; CARDINET, Jean; PERRENOUD, Philippe (org.). L'évaluation formative dans un enseignement différencié. Berne: Peter Lang. p. 153-183.

BLOOM, Benjamin S; HASTINGS, John Thomas; MADAUS, George F (1971). Handbook on formative and summative evaluation of student learning. New York: Mc Graw Hill.

BONNIOL, Jean-Jacques; VIAL, Michel (2001). Modelos de avaliação: textos fundamentais. Trad. de Cláudia Schilling. Porto Alegre: Artmed.

CASTRO, Marta Alexandra (2007). Processos de auto-regulação da aprendizagem: impacto de variáveis académicas e sociais. Dissertação de Mestrado. Instituto de Educação e Psicologia da Universidade do Minho.

CYR, Paul (1998). Les stratégies d'apprentissage. Paris: CLE International.

Cunha, Myriam Crestian Chaves da. Quando a autorregulação não ocorre na aprendizagem da língua estrangeira. Revista Intercâmbio, v. XXIX: 128-147, 2014. São Paulo: LAEL/PUCSP. ISNN 2237-759x

CUNHA, M. C.; MAGNO e SILVA, W. Aprender a Aprender: uma disciplina geradora de autonomia na formação do futuro professor de língua estrangeira. Anais - III Congresso Latino-Americano de Formação de Professores de Línguas, 2011, Taubaté. III Congresso LatinoAmericano de Formação de Professores de Línguas Tendências e Desafios na Formação de Professores de Línguas no Século 21. Taubaté: UNITAU, 2011. v. 1. p. 626-639.

DIAS, Paulo Agostinho Lourenço (2011). Práticas de avaliação formativa na sala de aula: regulação e feedback. Dissertação de Mestrado em supervisão pedagógica. Lisboa: Universidade Aberta.

FERNANDES, Domingos (2006). Para uma teoria de avaliação formativa. Revista Portuguesa de Educação, v. 19, n. 2, p. 21-50.

LUCKESI, Cipriano Carlos (2008). Avaliação da aprendizagem escolar: estudos e proposições. 19 ed. São Paulo: Cortez. p. 85-101.

MOTTIER-LOPEZ, Lucie (2012). La régulation des apprentissages en classe. Bruxelles: De Boeck.

O'MALLEY, J. Michael; CHAMOT, Anna Uhl (1990). Learning Strategies in Second Language Acquisition. Cambridge: Cambridge University Press.

PERRENOUD, Philippe (1991). Pour une aproche pragmatique de l'évaluation formative. Mesure et Évaluation en Éducation, Genève, v. 13, n. 4, p. 49-81.

PILLONEL, Marlyse; ROUILLER, Jean (2001). Faire appel à l'autoévaluation pour développer l'autonomie de l'apprenant. Cahiers Pédagogiques, n. 393, p. 30-32.

ROSÁRIO, Pedro Luiz (2001). Diferenças processuais na aprendizagem: avaliação alternativa das estratégias de autorregulação da aprendizagem. Psicologia, Educação e Cultura, Minho. v. V, n. 1, p. 87-102. 


\section{APÊNDICE}

\section{Grade de apuração dos documentos do corpus}

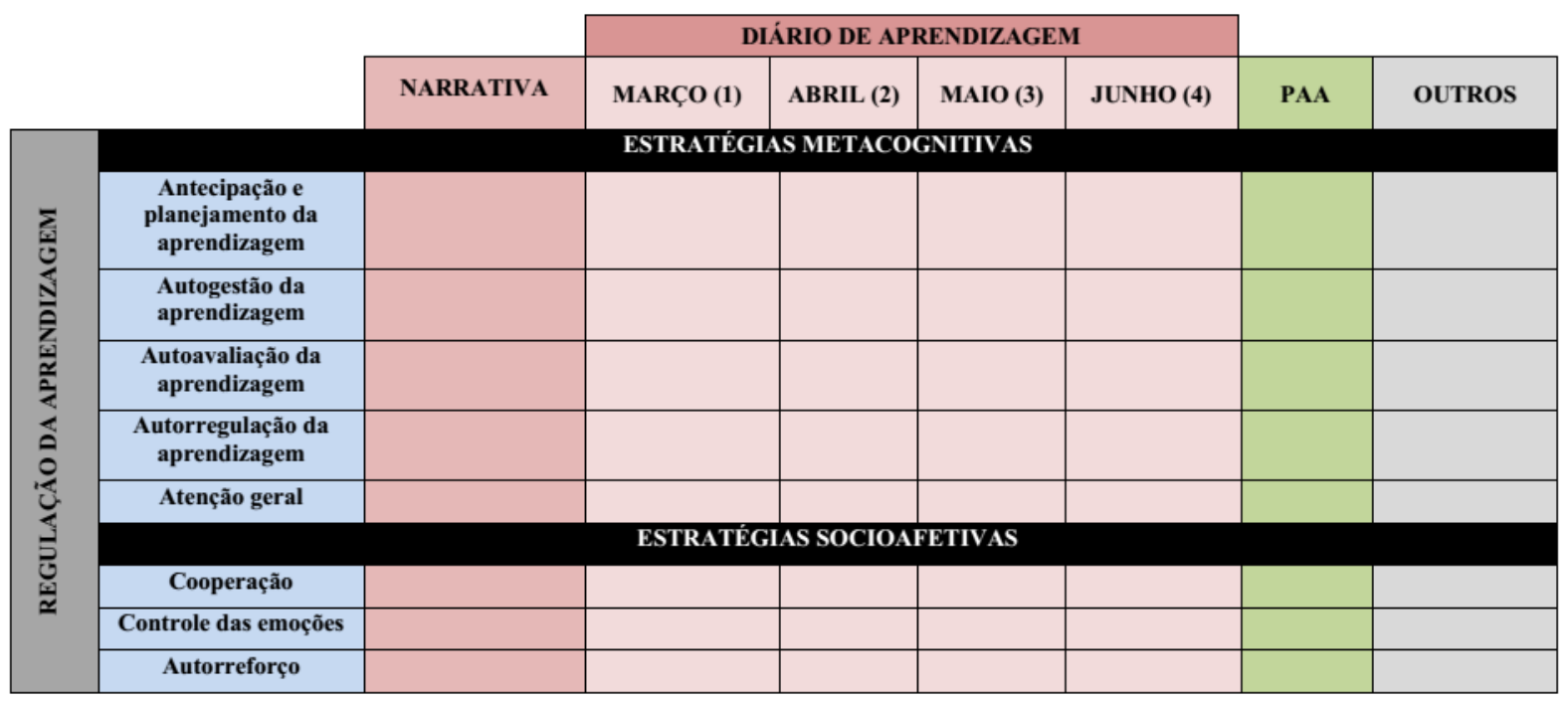

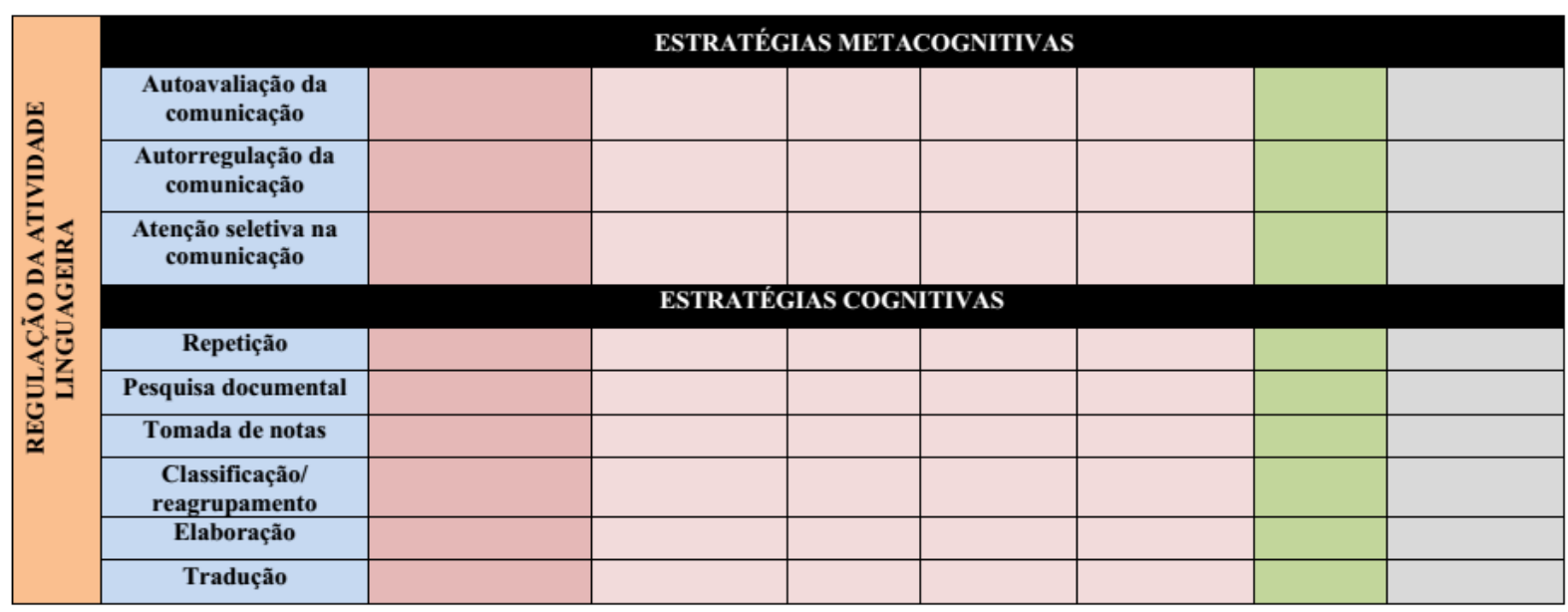

